\title{
USO INADEQUADO DE ÁREAS DE PRESERVAÇÃO PERMANENTE
}

\author{
Sérgio Campos ${ }^{1}$ \\ Mariana Wagner de Toledo Piza ${ }^{2}$ \\ Milena Montanholi Mileski² \\ Elen Fitipaldi Brasílio Carrega ${ }^{2}$ \\ Muriel Cicatti Emanoeli Soares ${ }^{3}$ \\ Mariana di Siervo ${ }^{3}$ \\ Gabriel Rondina Pupo da Silveira ${ }^{3}$
}

RESUMO: O grande desafio da população mundial é a conservação ambiental, pois as Áreas de Preservação Permanentes, que têm papel vital dentro de uma microbacia, por serem responsáveis pela manutenção, preservação e conservação dos ecossistemas ali existentes. O presente trabalho visou analisar os conflitos de uso do solo em áreas de preservação permanentes (APPs) da microbacia do Alto Capivara - Botucatu (SP) através do uso de Sistema de Informações Geográficas e de imagem de satélite digital. A área com 4551,19ha, situa-se entre as coordenadas geográficas: $22^{\circ} 51^{\prime} 57^{\prime \prime}$ a $22^{\circ} 57^{\prime} 55^{\prime \prime}$ de latitude S e $48^{\circ} 21^{\prime} 58^{\prime \prime}$ a $48^{\circ} 26^{\prime} 38^{\prime \prime}$ de longitude WGR. O mapa de uso do solo de 2006 foi obtido a partir da classificação supervisionada em imagem de satélite digital de

\footnotetext{
${ }^{1}$ Prof. Adjunto, Departamento de Engenharia Rural, Faculdade de Ciências Agronômicas/UNESP. seca@fca.unesp.br.

${ }^{2}$ Discentes do Programa de Pós-Graduação em Agronomia - Energia na Agricultura da Faculdade de Ciências Agronômicas/UNESP. seca@fca.unesp.br

${ }^{3}$ Discente do Curso de Graduação em Agronomia da Faculdade de Ciências Agronômicas/UNESP. mcesoares@fca.unesp.br
} 
23/10/2006. Na identificação digital dos alvos foram utilizadas as chaves de interpretação para imagens e as áreas foram determinadas através do software SIG - IDRISI. Os conflitos de uso nas áreas de preservação permanente foram analisados ao longo da rede

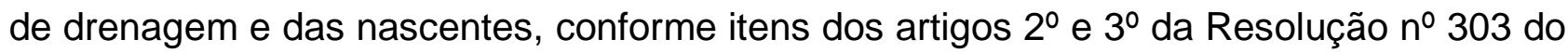
CONAMA. A área de APP discriminada ao longo da rede de drenagem foi de 416,5 ha $(9,15 \%)$. No entanto, 201,15ha da área de APP está ocupada com pastagem (48,3\%), reflorestamento (1,23\%) e $0,48 \%$ por área urbana de forma inadequada (conflito). Portanto, quase $50 \%$ de área de APP vem sendo parcialmente utilizada adequadamente.

Palavras Chaves: microbacia, sensoriamento remoto e Software CARTALINX.

\section{INTRODUÇÃO}

As áreas de proteção permanentes forma instituídas para preservar o meio ambiente, devendo estar cobertas com vegetação original, pois a cobertura vegetal minimiza os efeitos do processos erosivos e a lixiviação dos solos, contribuindo para a regularização do fluxo hídrico.

O levantamento e o mapeamento das degradações sofridas pelo meio ambiente é muito importante no conhecimento da realidade uso da terra e suas relações com as áreas de proteção permanentes, pois permitem estudos e planejamentos de atividades urbanas e rurais, bem como fornecem indicação de áreas propícias à exploração agrícola, pecuária ou florestal, previsão de safras e planejamento urbano.

A recuperação, conservação e exploração sustentável dos recursos naturais exigem conhecimentos das suas propriedades e da situação em relação aos efeitos antrópicos, pois o diagnóstico destes recursos relacionados com os problemas ambientais é uma excelente ferramenta na resolução dos problemas e tomada de decisões por parte do planejador, como os conflitos de uso da terra em relação às áreas de proteção permanentes. Desta forma, essa pesquisa visou determinar o uso da terra e sua relação com as áreas de proteção permanentes do Ribeirão Indaiá - Botucatu (SP), através de técnicas de geoprocessamento. 


\section{MATERIAL E MÉTODOS}

O presente trabalho está sendo desenvolvido na microbacia do Alto Capivara, situada na porção norte do município de Botucatu (SP). A área com 4551,19ha, situa-se entre as coordenadas geográficas: $22^{\circ} 51^{\prime} 57^{\prime \prime}$ a $22^{\circ} 57^{\prime} 55^{\prime \prime}$ de latitude $S$ e $48^{\circ} 21^{\prime} 58^{\prime \prime}$ a $48^{\circ} 26^{\prime} 38^{\prime \prime}$ de longitude WGR.

Os pontos de controle no processo de digitalização do mapa de ocupação do solo foram obtidos da Carta Planialtimétrica editada pelo Instituto Brasileiro de Geografia e Estatística - IBGE em 1969, folha de Botucatu (SF-22-R-IV-3), escala 1:50.000.

A interpretação das classes de uso e cobertura do solo foi feita com base na imagem de satélite digital, bandas 3, 4 e 5 do Sensor TM, do LANDSAT 5, da órbita 220, ponto 76, quadrante A, passagem de 23/10/2006, através do método de classificação em tela.

As imagens foram georreferenciadas no ENVI 4.2, e os pontos de controle utilizados foram obtidos da carta planaltimétrica de Botucatu, previamente georreferenciada. Posteriormente, foram exportadas para o IDRISI, onde foram feitas as composições RGB para cada uma das datas. Tais composições foram convertidas para o formato BMP através do CartaLinx, para então serem interpretadas.

Depois de identificadas as diferentes classes de uso e cobertura do solo, os polígonos vetorizados foram exportados para o ArcView 3.2 para a elaboração do mapa final e quantificação das áreas.

Inicialmente, através do software Arc View 3.2, foi realizado o georreferenciamento, utilizando-se para isso da carta topográfica de Botucatu, escala de 1:50000 e um GPS (Global Positioning System) para coleta de dados em campo.

O recorte da área na imagem digital foi realizado segundo os limites geográfico da área através do software ARCVIEW. Posteriormente, o mapeamento da área feito através da tela do monitor obedecendo aos padrões de análise, o qual se baseia em princípios como cor, tonalidade, textura, forma, grupamento, tamanho (elementos utilizados em fotointerpretação) e sombra.

As áreas de preservação permanente foram definidas ao longo dos cursos d'água do Ribeirão Indaiá, sendo utilizado a operação Buffer Selected Features do software ArcView 3.2, a qual proporcionou com que se fosse criado um buffer de 50 metros de raio das 
áreas das nascentes e um buffer de 30 metros de cada lado da drenagem ao longo do leito do córrego, com isso resultando no mapa de APPs, fundamentado na resolução CONAMA n 303/2002, Art. $3^{\circ}$ "constitui Área de Preservação Permanente a área situada em faixa marginal, medida a partir do nível mais alto, em projeção horizontal, com largura mínima de trinta metros, para o curso d'água com menos de dez metros de largura", e no Código Florestal (Lei 4.771/1965), que considera essas áreas, cobertas ou não por vegetação nativa; "com a função ambiental de preservar os recursos hídricos, a paisagem, a estabilidade geológica, a biodiversidade, o fluxo gênico da fauna e flora, proteger o solo e assegurar o bem estar das populações humanas".

O mapeamento e a quantificação dos conflitos de uso da terra em áreas de preservação permanente foram realizados usando-se álgebra de mapas. Os procedimentos foram executados no ambiente Raster Calculator do módulo Spatial Analyst do ArcGIS.

\section{RESULTADOS E DISCUSSÃO}

O uso da terra na microbacia do Alto Capivara - Botucatu (SP) mostra que as florestas Estacional Semicidual (Figura 1 e Quadro 1) vêm predominando em quase 70\% da área em 2006, devido a presença de solos pobres e da fácil mecanização nessas áreas.

As florestas, elementos importantes na preservação ambiental, representam mais $22 \%$ da área. Estas classes são formadas praticamente por cerrado, cerradão, floresta estacional semicidual, matas ciliares e transição floresta estacional/cerradão. As matas ciliares é uma formação florestal que acompanha os rios de pequeno porte e são corredores fechados sobre a rede de drenagem. Segundo o Código Florestal, a reserva mínima de florestas deve ser de $20 \%$. Esses dados permitem inferir que a microbacia vem sendo preservado ambientalmente $(22,26 \%)$, devido à alta porcentagem de florestas na microbacia. 


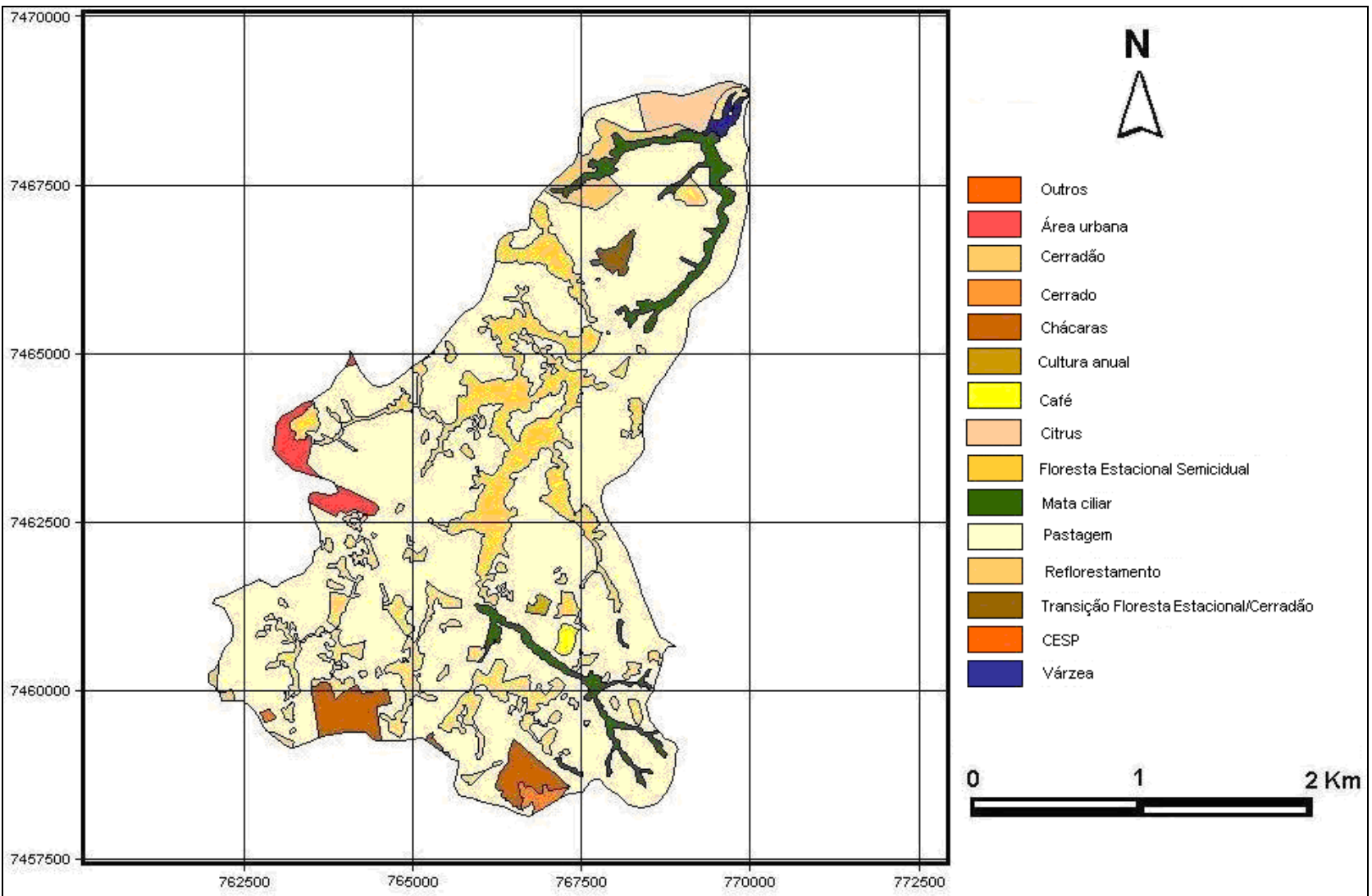

Figura 1. Uso e cobertura do solo da microbacia do Alto Capivara - Botucatu (SP), em 2006.

A transformação na cobertura vegetal vem acontecendo de forma dinâmica na microbacia, ao longo do tempo, com a região sofrendo sensíveis mudanças nas paisagens nos últimos anos, caracterizadas principalmente expansão da silvicultura.

Os conflito de usos em áreas de APPs (Figura 2), o buffer gerado num raio de 50m ao redor das nascentes somam $376992 \mathrm{~m}^{2}$, representando cerca de $0,17 \%$ da superfície da microbacia, enquanto que ao longo da rede de drenagem estudada com uma largura de $30 \mathrm{~m}$ ocuparam $8,32 \%$ da área total da microbacia.

Os 416,5ha de áreas de APPs ao longo da rede de drenagem estão ocupados com reflorestamento $(1,23 \%)$, área urbana $(0,48 \%)$ e pastagem $(48,30 \%)$ de forma inadequada (conflito). Portanto, quase $50 \%$ de área de APP vêm sendo utilizados adequadamente, demonstrando que a microbacia está parcialmente conservada ambientalmente segundo o Código Florestal Brasileiro vigente (1965). 


\section{FÓRUM AMBIENTAL DA ALTA PAULISTA}

Volume VI - Ano 2010

Instituição Organizadora: ANAP - Associação Amigos da Natureza da Alta Paulista

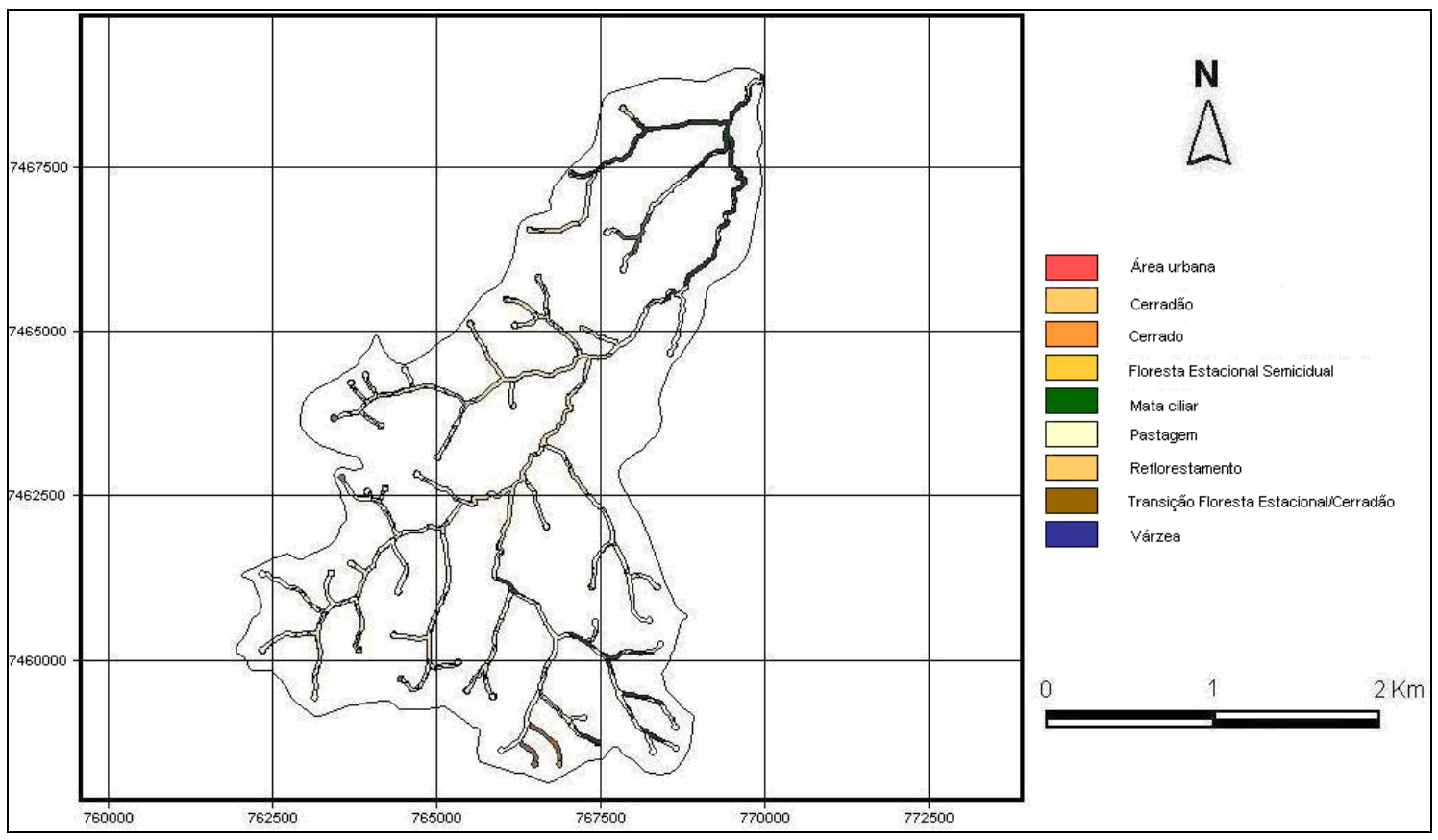

Figura 2. Conflito de uso do solo em APPs da microbacia do Alto Capivara - Botucatu (SP), em 2006.

A mata de galeria protege o solo contra o impacto direto das gotas das chuvas, diminuindo a velocidade de escoamento superficial e favorecendo a infiltração de água no solo (Silveira et al., 2005). 


\section{FÓRUM AMBIENTAL DA ALTA PAULISTA}

Volume VI - Ano 2010

Instituição Organizadora: ANAP - Associação Amigos da Natureza da Alta Paulista

Quadro 1. Classes de uso do solo e conflito de uso em APP's da microbacia do Alto Capivara - Botucatu (SP), em 2006.

\begin{tabular}{|c|c|c|c|c|}
\hline \multirow{2}{*}{ Classes de uso da terra } & \multicolumn{3}{|c|}{ Área da microbacia } \\
\cline { 2 - 5 } & Uso da terra & \multicolumn{2}{|c|}{ Conflito } \\
\cline { 2 - 5 } ha & $\%$ & ha & $\%$ \\
\hline Área urbana & 62,09 & 1,36 & 2,00 & 0,48 \\
\hline Cerradão & 286,17 & 6,29 & & \\
Cerrado & 16,06 & 0,35 & & \\
Chácaras & 119,33 & 2,62 & & \\
Cultura anual & 6,75 & 0,15 & & \\
Café & 10,96 & 0,24 & & \\
Citrus & 63,60 & 1,40 & & \\
Floresta Estacional Semicidual & 516,57 & 11,35 & & \\
Mata ciliar & 174,52 & 3,83 & & \\
Pastagem & 3173,43 & 69,72 & 201,15 & 48,30 \\
Reflorestamento & 82,67 & 1,82 & 5,13 & 1,23 \\
Transição Floresta & 19,95 & 0,44 & & \\
Estacional/Cerradão & & & & \\
CESP & 2,87 & 2,53 & & \\
Várzea & 15,82 & 0,35 & & \\
Outros & 0,74 & 0,02 & & \\
Total & 4551,53 & & 208,28 & 50,01
\end{tabular}

Neste estudo foram analisados os conflitos de uso nas áreas de preservação permanente, somente ao longo da rede de drenagem da microbacia, desconsiderando-se as demais áreas de APPs, uma vez que o relevo da área varia de plano a ondulado.

\section{CONCLUSÕES}

O estudo realizado na microbacia do alto Capivara - Botucatu (SP) mostrou que o uso inadequado da terra em áreas de preservação permanente é consideravelmente baixo, 
pois o uso antrópico (inadequado) chega a 50,01\% das APPs, Os mapas de uso da terra podem servir como poder de fiscalização futuramente pelos Órgãos Públicos, bem como par identificação e localização das áreas de conflitos de uso da terra. O uso de técnicas de sensoriamento remoto através do emprego de produtos orbitais do Landsat mostrou-se eficientes; a definição do uso do solo, na integração dos dados georreferenciados dentro de um banco de dados mostrou ser uma ferramenta fundamental para o planejamento de uso do solo numa microbacia, bem como a sua utilização no atendimento à legislação ambiental, principalmente nas áreas de APPs. O Sistema de Informações Geográficas Arc View 3.2 foi eficiente na discriminação das classes de uso do solo, mostrando que $69,72 \%$ da área é ocupada com pastagem e que a área de APP da microbacia é de 416,5ha, onde 50,01\% está sendo usado inadequadamente (conflito) por pastagem, reflorestamento e área urbana.

\section{REFERÊNCIAS BIBLIOGRÁFICAS}

Brasil. Lei $n^{\circ}$ 4.771, de 15 de Setembro de 1965, que institui o novo Código Florestal.

CONAMA (Brasília, DF) Resolução № 303, de 20 de março de 2002. Diário Oficial [da República Federativa do Brasil], Brasília, 13 de maio de 2002.

Costa, T.C.C.; Souza, M.G.; BRITES, R.S. Delimitação e caracterização de áreas de preservação permanente, por meio de um sistema de informações geográficas. In Anais VIII Simpósio Brasileiro de Sensoriamento Remoto, Salvador, Brasil, INPE, 1996. p. 121-127.

MAGALHÃES, C.S.; FERREIRA, R.M. Áreas de preservação permanente em uma microbacia. Informe Agropecuário, Belo Horizonte. V. 21, n.207, p. 33-39, 2000.

Rocha, C. H. B. Geoprocessamento: tecnologia transdisciplinar. Juiz de Fora, MG: Ed. do Autor, 2000. 220p.

Silveira, E. M. O.; Carvalho, L. M. T.; Silva, A. M. Uso conflitivo do solo nas áreas de preservação permanente no município de Bocaina de Minas/MG In: XII Simpósio Brasileiro de Sensoriamento Remoto, 2005, Goiânia - GO. Anais... São José dos Campos: INPE, 2005. 